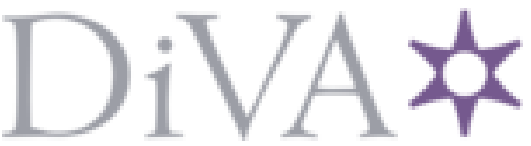

http://www.diva-portal.org

\title{
Postprint
}

This is the accepted version of a paper published in . This paper has been peer-reviewed but does not include the final publisher proof-corrections or journal pagination.

Citation for the original published paper (version of record):

Weurlander, M., Söderberg, M., Scheja, M., Hult, H., Wernerson, A. (2012)

Exploring formative assessment as a tool for learning: Students' experiences of different methods of formative assessment.

Assessment and Evaluation in Higher Education, 37(6): 747-760

https://doi.org/10.1080/02602938.2011.572153

Access to the published version may require subscription.

N.B. When citing this work, cite the original published paper.

Permanent link to this version:

http://urn.kb.se/resolve?urn=urn:nbn:se:kth:diva-182476 


\title{
RESEARCH ARTICLE
}

\section{Exploring formative assessment as a tool for learning: Students' experiences of different methods of formative assessment}

\author{
Maria Weurlander* ${ }^{\mathrm{a}}$, Magnus Söderberg ${ }^{\mathrm{d}}$, Max Scheja ${ }^{\mathrm{c}}$, Håkan Hult ${ }^{\mathrm{b}}$ \& Annika \\ Wernerson $^{\mathrm{b}}$ \\ ${ }^{a}$ Department of Learning, Informatics, Management and Ethics (LIME), Karolinska Institutet, \\ Sweden, \\ ${ }^{b}$ Department of Clinical Science, Intervention and Technology (CLINTEC), Division of Renal \\ Medicine, Karolinska Institutet, Sweden, \\ ${ }^{c}$ Department of Education, Stockholm University, Sweden, \\ ${ }^{d}$ formerly Department of Laboratory Medicine, Division of Pathology, Karolinska Institutet, \\ Sweden, now Safety Assessment, AstraZeneca Sweden.
}

*Corresponding author: Email: maria.weurlander@ki.se

This is an Accepted Manuscript of an article published by Taylor \& Francis in Assessment \& Evaluation in Higher Education on 12 June 2011, available online: http://www.tandfonline.com/10.1080/02602938.2011.572153

To cite this article: Weurlander, M., Söderberg, M, Scheja, M., Hult, H. \& Wernerson, A. (2012) Exploring formative assessment as a tool for learning: Students' experiences of different methods of formative assessment. Assessment \& Evaluation in Higher Education 37(6):747-760. 


\section{Weurlander et al}

Accepted version

\section{Abstract}

This study aims to provide a greater insight into how formative assessments are experienced and understood by students. Two different formative assessment methods, an individual, written assessment and an oral group assessment, were components of a pathology course within a medical curriculum. In a cohort of 70 students, written accounts were collected from seventeen students and group interviews were carried out to explore the students' experiences of these two forms of assessment. All students were engaged in both assessment methods, which were conducted a few weeks apart, and data were collected soon after each assessment. Our findings suggest that formative assessments motivate students to study, make them aware of what they have learned and where they need to study more. Thus, formative assessment can act as a tool for learning, contributing to the process and outcomes of learning. A closer look at students' experiences of each form of assessment reveals interesting differences.

Keywords: formative assessment, higher education, students' experiences, student learning 
M. Weurlander et al

Accepted version

\section{Introduction}

Assessment is about making judgements on the quality of students' performance (Knight 2006). It can be used both to summarize students' achievements in order to award some kind of certification (summative assessment) and to give feedback to students in order to support learning (formative assessment) (Falchikov 2005; Sadler 1989; Yorke 2003). These two principle aims are closely linked, and apply to most assessment tasks, though to a varying extent (Boud 2000). In the present study, formative assessment is defined as activities where judgements are made about the quality of students' achievements, and where this information is used to facilitate student learning (Black \& Wiliam 1998; Sadler 1989).

It has been argued that formative assessment is under-theorised (Yorke 2003) and more studies are needed to gain a better understanding of the various ways in which assessment practice affects student learning. Students' experiences of assessment practice are an important source of information on the nature of the relationship between assessment and learning. The purpose of the present study is to contribute to our understanding of formative assessment by exploring students' experiences of two completely different formative assessments made during a course.

Assessment practice is closely linked to the overall teaching context and the teacher's view of his or her role (Black \& Wiliam 1998). In addition, all forms of assessment can be regarded as a reflection of the epistemological beliefs of each practitioner. This means that teachers construct their assessment tasks according to the knowledge they consider important and their view of how this should be assessed in a particular context (Säljö 2000; Lindberg-Sand 2003) - ideas which in turn are influenced by the local teaching and learning regime (Trowler \& Cooper 2002). Furthermore, teachers' orientation to assessment range along a continuum, from a focus on knowledge retention to an emphasis on knowledge construction and transformation, and is related to their orientation to teaching and learning (Samuelowicz \& Bain 2002). At one end of the continuum, assessment is perceived as a form of knowledge control, where the outcome of learning is seen as acquired factual knowledge or skills that can either be correct or incorrect (Falchikov 2005; Samuelowicz \& Bain 2002; Serafini 2000-2001; Sfard 1998). This view is consistent with a structure-and-process based curriculum where there is a strong focus on content (Carraccio et al. 2002). At the other end of the continuum, assessment is believed to be a means of facilitating learning and supporting students in developing their own understanding of the subject matter (Samuelowicz \& Bain 2002). This orientation to assessment is consistent with a view that has been gaining ground in recent years, the concept of assessment as learning, where the outcome of learning is seen as complex and is defined in terms of quality of understanding or degree of expertise (Sadler 1989). Assessment is considered to be an integral part of teaching and learning, and the focus is on student involvement and authentic, meaningful assessment, 
leading to the development of a variety of assessment forms (Falchikov 2005). This view is consistent with a competence-based curriculum which emphasises competence and capability rather than recollection of factual knowledge (Carraccio et al. 2002).

Assessment sends a strong message to students about what counts as knowledge in a particular learning environment. Snyder (1971) refers to this message as the hidden curriculum. Students' perceptions of assessment requirements are closely related to their approaches to learning (Marton \& Säljö 1997; Ramsden 1997; Scouller 1998, Ramsden 2003; Struyven et al. 2005). Assessments which focus on recall of factual knowledge tend to steer students towards surface approaches to learning, whereas assessments which emphasise application and comprehension tend to encourage deep approaches to learning. Sambell and McDowell (1998) conducted a study which explored students' experiences of different innovative assessments. Their conclusion was that the same assessment has different meanings for different students. This suggests that students' perceptions of the requirements of the assessment influence their approach to learning.

Although formative assessment can be designed in many different ways to accommodate different aims, the main function is to generate feedback on students' performance in order to improve learning (Falchikov 2005; Sadler 1998). Feedback is therefore a key component in formative assessment, and students need to understand and be able to act on the feedback they receive in order to improve their learning (Black \& Wiliam 1998; Nicol \& MacfarlaneDick 2006; Sadler 1989; Sadler 1998). However, to improve their performance, students need to be aware of the required level or performance standard. Moreover, they need to be able to compare the quality of their own work to the required level and have a strategy to close the gap (Sadler 1989).

The assumption underpinning formative assessment is that it has a positive impact on student learning, a view which is supported by research findings. For instance, Black and Wiliam (1998) conclude that formative assessment which gives students supportive feedback does indeed improve their learning. More recently, Carrillo-de-la-Peña (2009) showed that students who took part in formative assessment achieved higher marks in the final assessment than students who did not participate. The study involved students from different branches of the health sciences and the formative assessments were mid-term tests. Interestingly, it seemed that taking part in the formative assessment was more important than being successful, which supports the importance of the role of feedback in formative assessment (ibid). Hattie and Jaeger (1998) argue for a model where assessment is an integral part of the teaching and learning process, and where feedback has a key role in enhancing students' achievements.

Taken as a whole, research on assessment shows that the design of assessment tasks influence student learning in a number of ways. It sends messages about what counts as important knowledge, it has an impact on students' approach to learning and it gives feedback to students about their 


\section{Weurlander et al \\ Accepted version}

learning. However, during their undergraduate studies students are likely to encounter several different types of assessment designed by different teachers, each of whom may have a different orientation to assessment. How does this affect students' experiences of assessment? In order to better understand this more fully, we chose an undergraduate course with two different types of formative assessment, which we aimed to explore from students' point of view. We chose an exploratory research design, rather than a comparative study. The specific research questions were as follows: In which ways can these methods of formative assessments act as tools for learning? How do students experience and perceive these two types of formative assessment?

\section{The present study}

The two different types of formative assessment studied were as follows: 1) an individual written assessment with mainly factual questions, and 2) an oral assessment which encouraged students to solve problems in groups. These assessments were a well-established part of a nine-week lecture-based course in pathology (the study of diseases), which also involved other teaching and learning activities such as autopsies, case seminars and seminars during which students discussed microscopic images of tissue. The medical curriculum at the Swedish university which provided the context for the study focused on basic sciences (cell biology, anatomy, physiology, etc.) in the first two years, followed by three and a half years of clinical courses (surgery, medicine etc.). Pathology was taught at the end of the second year. The two quite different types of formative assessment in the above-mentioned pathology course served as study objects, and were chosen because of their different focus. One concentrated on right/wrong answers, individual performance and delayed feedback, where the other focused on understanding/problem solving, group performance and immediate feedback. The individual assessment largely reflected a view of assessment as knowledge control and the group assessment reflected the concept of assessment as learning. In addition to the two formative assessments, there were two summative assessments at the end of the course: a group assessment where students solved problems together and an individual written exam.

In the present study, the first individual assessment represents an 'inherent' assessment influenced by tacit assumptions and traditions (Trowler \& Cooper 2002), whereas the second was developed with the explicit aim of improving learning by facilitating the integration of knowledge and discussion between students and teachers.

\section{The assessment methods}

The individual assessment

This was a traditional written assessment which had been a component of the pathology course for many years. It was held after the first two weeks of the 
course and covered general pathology, i.e. mainly general mechanisms of diseases such as inflammation and tumour development. This assessment consisted of about twenty questions which required short answers from a few words to a few sentences and mainly emphasised the recall of factual knowledge. Examples of questions were: "What are the causes of tissue damage due to an inflammatory response?" and "Which factors influence the 'selection' of target organ during the spread of a tumour from its original site (metastasis)?". Feedback was given a few weeks later, in the form of right or wrong answers and a summarised score. It was not mandatory for students to participate in this assessment but passing the written formative assessment gave them a few credit points in the final, individual, summative exam. In other words, doing well in the formative assessment gave students a small reward in terms of extra points, but they could choose not to take the formative assessment without consequences.

\section{The group assessment}

The group assessment was an oral assessment procedure which required students to solve problems in groups. This form of assessment was developed and implemented with the aim of emphasising critical thinking and facilitating understanding of the course content. It was held after about six weeks and covered most of the organ-specific pathology content of the course. The assessment consisted of five different clinical cases. The students were given cards with different pieces of information regarding the cases, including written patient histories, laboratory tests, printed microscopic images and surgical specimens. They also received written descriptions of microscopic images and written information on the mechanisms of the diseases. Some of the cases were rather similar, e.g. they involved diseases in the same organ and/or with similar symptoms. To make the task even more challenging, a few extra cards were provided with information irrelevant to the five cases. The students worked in groups of 6-8 for 90 minutes, matching the different cards to the patient histories for each case. The task could be described as a kind of puzzle which had to be solved or a matrix to be completed, where the students needed to discuss the cases, explain their thoughts to one another and negotiate in order to reach consensus. At the end, the students wrote down on a piece of paper which cards they thought belonged to each patient history. They were also encouraged to suggest a diagnosis in each case. The teacher gave oral feedback immediately, and this often led to a discussion about the cases. Students were required to pass this group assessment in order to be entered for the final exam. To pass, the group had to assemble correctly a certain number of pieces in the puzzle, i.e. they were required to work out, as a group, how different pieces of clinical information were connected. If the group failed, they had to take the assessment again by completing a similar task. In our experience, all students tended to participate actively in the task, though their specific contribution could vary. 


\section{Research methodology}

The research presented here was conducted within a constructivist research tradition, which acknowledges that both researchers and participants act within constructed realities, that data is constructed as a result of interaction between the researcher and informants, and that analysis as a process is informed by the researcher's prior knowledge and experiences (Denzin \& Lincoln 2003). This study also stems from the research tradition which approaches the experience of learning from the students' perspective (Marton 2005). Underpinning this research is the concept of learning as a process of striving for meaning, and a qualitative change in understanding, where learners discern and take into account more and more aspects of phenomena in the world around them (Dahlgren 2005). Moreover, learning is seen as situated in, and influenced by the socio-cultural context in which it occurs (Leach \& Scott 2003; Vygotsky 1978).

This study took an exploratory approach to research, aiming to understand students' experiences. It can be considered a generic qualitative research approach (Caelli et al 2003) inspired by grounded theory (Charmaz 2006; Corbin \& Strauss 2008).

\section{Data collection and analysis}

Data were collected through group interviews and written accounts. Group interviews were chosen as we wished to capture the students' immediate thoughts and their experiences of the two assessments. Interaction between participants can also stimulate further thoughts and comments (Patton 2002). Medical students who were taking the pathology course in the autumn of 2007 were asked to participate in the study, and respondents were selected who had experienced both formative assessments. Seventeen students from the total of 70 volunteered to reflect on their experiences in writing, which they did two to four days after each assessment (34 written accounts in total), and another group of seven students participated in semi-structured group interviews immediately after each assessment (two group interviews in total). The groups included a mixture of male and female students as well as young and more mature students, in order to maximise variation in their experiences of assessment practices. Of the 17 students who wrote down their reflections, four were international students taking this particular course. To improve the trustworthiness of the analysis, a second round of data was collected in the autumn of 2008. A convenience sample of nine students was then interviewed immediately after each assessment (two group interviews in total).

The students in this study (both cohorts) were asked to describe, in broad terms, their own experiences of each form of assessment. They were not asked to compare them as we wished to capture their immediate experiences of each assessment and not their comparison of the two. We used an explorative research design and asked open questions such as 'Tell me about 
the individual assessment' and 'What are your thoughts about the group assessment?'. The group interviews were carried out by the first author who had no other relationship to the students other than as a researcher. To create a relaxed atmosphere and reduce the asymmetry between researcher and participants, the researcher followed the students during the course and participated in many of the teaching sessions. The study followed ethical guidelines on research involving human subjects, and written informed consent was obtained from all students prior to the data collection. The interviews were recorded electronically and fully transcribed.

All data, interview transcripts and written reflections, were treated as one data set. Data were coded line by line and the codes were clustered into groups. At first, analytical themes were constructed around the two different assessment methods. Then, as the analysis moved to a more abstract level, the emphasis shifted to formative assessments as a tool for learning. Throughout the process, memos were written in order to document every step of the analysis (Charmaz 2006, Corbin \& Strauss 2008). The themes and categories were regularly compared to similar themes and categories as well as to the original data.

\section{Findings}

Our findings show that formative assessments are an important tool for students' learning in three areas: motivation to study, awareness of their own learning and the effects on learning, in terms of both processes and outcomes, (see Figure 1). The findings are first presented according to each main area, and this is followed by a closer look at each type of formative assessment in relation to the three areas.

(insert figure 1 about here)

\section{Motivation to study}

Formative assessment influenced the students' motivation to study in several ways. For many students the formative assessments seemed to act as external motivators. Students felt pressure to study for the assessment and said that they needed some stress or deadline to motivate them to study, especially early in a long course. 'I need the extra stress to go back... because even if I have read it before I need this 'assessment stress' to go back and rehearse once or twice more to make it stick' (individual assessment, group interview, ind. assm, interview). This suggests that the assessment triggers extrinsic aspects of motivation which, in turn, have an impact on certain actions, in this case to study and practice for the assessment. Furthermore, when they had several formative assessments during a course, students seemed to study more consistently.

There was also evidence of intrinsic motivation such as a growing interest in the subject as a result of studying for the assessment. Students noted that they retained information more easily when they were interested in a 
subject. Moreover, an assessment task can be stimulating and challenging in itself, and thereby trigger intrinsic motivation, as was the case with the group assessment. 'The group assessment was fun and challenging, and gave the much longed-for overall picture that is so difficult to put together on your own.' (group assm, wr reflection).

\section{Awareness of own learning}

As well as influencing motivation, we found that formative assessment can give students feedback on their progress, which in turn makes them aware of their own learning. The experience of whether or not they were able to complete the task or answer the questions gave students an indication of how much they had understood and where more study was required: 'There were a lot of things I didn't know on the assessment and if I pass, it will be just barely, which makes me feel a bit stressed.' (ind assm, wr reflection). In other words, students themselves reflected on their own progress and weaknesses in relation to the assessment tasks. Formative assessments also gave students clues on what counts as important in the course, i.e. what kind of questions and which knowledge might come into the final exam.

\section{Assessment as a tool for learning - process and product}

Formative assessments contributed to students' learning both by influencing the learning process (how students learn) and by affecting the learning outcome (what they learn). The students felt they learned by explaining their thinking to others, either by formulating a written answer to a question in the individual assessment or by expressing their views orally and reasoning aloud during the group assessment. 'Something can be crystal clear in your head, and then you have to explain it in writing to a teacher [...]. Then you suddenly have to think it through and really be able to explain it [...] so that someone else will understand how you are thinking.' (ind assm, interview). In addition, the assessment task, which was designed in such as way as to require a problemsolving approach, seemed to encourage students to use their knowledge in order to complete the task: 'It also gave us an opportunity to use that knowledge in a problem-solving way, which almost mimics how it is in reality.' (group assm, wr reflection).

Our findings also suggest that formative assessment contributed to the learning outcome. Many students mentioned that they learned basic facts and details about diseases and obtained an overview of the subject, a sort of brief map of the content. Students believed that they needed this basic knowledge and overview to be able to understand the lectures that followed. Moreover, by reviewing the assessment and the experience of completing the assessment task, students seemed to be able to structure their knowledge and obtain a sense of 'wholeness' or interconnectedness and was about getting the 'bigger picture' and making connections with the real world. 'I learned a lot, 
partly to think in a bigger context, i.e. to see the disease behind the microscopic images, and partly to connect the biological mechanisms of the disease to the clinical context.' (group assm, wr reflection).

\section{Students' experiences of the two different methods of assessment}

A closer look at the students' experiences of the two forms of assessment reveals differences in how each method affects motivation to study, awareness of one's own learning, and how, therefore, they act as tools for learning. The following section describes the findings with regard to each form of assessment, and these are summarised in Table 1.

The individual assessment

What comes to the fore in the analysis of students' experiences of the individual assessment is that it was primarily a trigger for extrinsic motivation. The pressure to study for the formative assessment affected how much time students spent on studying. For instance, students mentioned that they would not have spent as much time studying if they had not had to take the individual formative assessment. A reward in the form of a few extra credits in the final exam seemed to motivate some students to study for the individual assessment. Students also seemed to act strategically, in that they spent time studying rather than doing other things and focused their studies on the content of the lectures rather than following the syllabus. 'The formative assessment made me go through lecture notes and hand-outs to a greater extent than I would have done otherwise.' (ind assm, wr reflection).

The students' awareness of how much they knew or did not know was a theme common to both assessments and appears to have been the main source of feedback. However, in terms of the individual assessment, the lack of immediate feedback from teachers was mentioned. 'We don't know when we will get the results from the assessment or if we will get any feedback on our answers.' (ind assm, wr reflection).

The individual assessment influenced the students' learning process largely because they were forced to explain their thoughts in writing. 'If you sit there for two hours and write long answers, just doing that is a pretty good way to learn.' (ind assm, interview). Studying for the individual assessment gave students an overview of the subject and they learned basic facts and terminology. The students felt that they needed this basic knowledge to be able to understand the rest of the course. Students seemed to hold the idea that one needs to learn the basic facts first, and that a deeper understanding of the content would comes later. 'For me personally, studying for the individual assessment helps to build a framework to which knowledge from the following modules can easily be added. I think that the "aha-experiences" and the understanding come later.' (ind assm, interview). 
M. Weurlander et al

Accepted version

The group assessment

What stands out in the analysis of the oral group assessment are two things: firstly, the assessment format itself seemed to stimulate intrinsic motivation, and secondly, it helped students to connect their knowledge to reallife contexts and it contributed to a sense of 'wholeness'. Many students described the assessment task as fun, challenging and interesting. However, students also seemed to feel pressure to study for this assessment, which indicates that assessment tasks can trigger both extrinsic and intrinsic motivation. 'The group assessment was very instructive, fun and exciting. [...]. It was a good opportunity to learn. Partly because as usual you needed to study beforehand, and it is good to keep up with reading during the course.' (group assm, wr reflection).

Not only did the group assessment provide internal feedback, but students also noted that feedback from teachers led to a valuable discussion of the cases at the end of the group assessment. 'You received clarifications from the teacher that were valuable' (group assm, wr reflection).

The group assessment seemed to influence students' learning in different ways to the individual assessment. Students mentioned that the task helped them to think from the patient's perspective and connect their knowledge of diseases to a patient history, rather than just learn a number of symptoms of a disease. This helped them to understand how facts are related, and to learn select the most important factors in evaluating different symptoms. The group assessment required the students work in groups to solve the cases and this helped their learning process. They learned by listening to other students' explanations, which gave them new insights. In order for the group to reach consensus on how to solve the puzzle, students had to discuss and sometimes argue their own point of view. 'I learned a lot! Unlike a traditional formative assessment, you were informed of the others' knowledge and could add this to your own' (group assm, wr reflection). Students needed each other to solve the cases, and since they all had slightly different knowledge they learned from each other during the discussions.

(insert table 1 here)

\section{Discussion}

This study aimed to explore students' experiences of different methods of formative assessments within the same course. The findings show that formative assessment influenced the students' motivation to study, it made them aware of what they had learned, and therefore acted as a tool for learning which influenced both the process and outcomes of learning. The way the assessment methods were constructed was important for the students' experiences. The individual assessment method can be said to reflect a view of assessment as knowledge control focusing on factual knowledge, whereas the group assessment method expresses a view of assessment as learning focusing 
on understanding and application (Falchikov 2005; Serafini 2000-2001; Sfard 1998). Interestingly, despite these fundamental differences, both forms of assessment seemed to act as a tool for learning within this course. How can this be explained?

One explanation for why the individual assessment functioned as a tool for learning may have been the educational context in which the assessment was carried out. The students seemed to believe that learning generally involves memorising basic facts and terminology first and foremost, and then understanding the material later. The medical curriculum which formed the context for our study, built on this concept in that basic science was studied in the first two years followed by clinical courses in the subsequent years. The basic information was learned first and applied in context later. Scheja and Bonnevier (in prep) have found similar experiences of the medical students' view of their curriculum. In other words, the students appeared to have adopted the local teaching and learning regime of the curriculum (Trowler \& Cooper 2002) which may be why they did not question the focus on factual recall. In addition, the individual assessment in the present study appeared to be an important factor in the students' motivation to study. This could be due to the fact that the individual assessment came only two weeks into the course and the students had recently studied hard for the final exam of the previous course.

The group assessment may also have acted as a tool for learning because of the design of the task itself which captured the students' interest and focused on problem-solving and practical application. The group assessment helped students to apply their knowledge in a clinical context and to develop a sense of 'wholeness' or interconnectedness of the subject material. A similar case of students developing a sense of connectedness or provisional wholeness as a result of studying for exams has been described by Entwistle and Entwistle (1992). In addition, the group assessment was designed to facilitate collaboration between students, as they needed to solve the problems together. This required dialogue and discussion, which meant that the students had to explain and justify their thinking to each other. Notably, our findings also suggest that learning is facilitated in a similar way by thinking through and formulating written answers to questions.

Students' perceptions of the requirements of assessment influence the approaches they adopt to studying and learning (Entwistle \& Entwistle 1991; Marton \& Säljö 1997; Ramsden 2003; Scouller 1998). This suggests that the two assessments in the present study may have sent different messages to students about what counted as important knowledge in the same course since they represented different epistemological beliefs and were expressions of different orientations to assessment (Lindberg-Sand 2003; Samuelowicz \& Bain 2002). However, individual students perceive the demands of the same assessment differently (Sambell \& McDowell 1998). Our study confirmed that students often find innovative assessments meaningful and relevant (Falchikov 2005). The group assessment appeared to capture the students' interest; they 
found the task challenging and relevant for their future profession. Interest has, in turn, been found to be closely linked to intrinsic motivation which is often associated with a deep approach to learning (Entwistle 1988; Marton 2005). The strong focus on factual knowledge in the individual form of assessment and the extrinsic motivation felt by students may steer them instead towards a surface approach to learning. The data, however, indicates a movement from extrinsic to intrinsic motivation. Even though students felt pressured to study for the assessments, they became interested in the subject as they learned more. Moreover, the findings suggest that students have the intention to understand but the pathway to reach understanding involves memorisation, which the individual assessment encouraged. Understanding through memorisation has previously been described in Asian students in general (Kember 1996) and our findings suggest that this approach to learning may also be found in other contexts.

Both types of formative assessment seem to have facilitated student learning in this study, and our findings suggest that they complemented one another: one emphasising factual knowledge and the other clinically relevant problems. Students learn ways of thinking and practicing in a certain discipline as they engage in teaching, learning and assessment (Anderson \& Hounsell 2007). As previously discussed, the assumptions of teaching and learning medicine that underpin the curriculum in this study supports the idea of learning facts and concepts first and understanding them in a clinical context later. In medicine it is important to obtain a good grounding in factual information in order to understand the human body in both health and disease, and to be able to solve clinical problems. In this respect, the two formative assessments examined in our study complemented one another as tools for learning, despite their underlying epistemological differences.

Our findings suggest that students were made aware of their own learning through the experience of being able or unable to answer assessment questions or to contribute towards solving the group assessment. It seems that taking part in formative assessment can help students reflect on their performance, a process which has been described as internal feedback (Nicol \& Macfarlane-Dick 2006). The two formative assessments in this study probably gave students different feedback messages. The individual written assessment gave them hints about what kinds of questions they could expect in the final exam and whether they had learned enough basic facts. The group assessment, on the other hand, gave them an insight into how their peers reasoned in the discussions about the cases, and this in turn may have stimulated reflection on their own knowledge. In addition, clarifications from teachers provided feedback on what students knew and what they did not know. These findings raise the question of whether both methods of formative assessment investigated in this study contribute to an increase in students' metacognitive awareness. 


\section{Weurlander et al \\ Accepted version}

\section{Concluding remarks}

The findings of this study support the idea that formative assessment methods can act as tools for learning by affecting students' motivation to study and by making them aware of their own learning, thus contributing to their learning process. Although this is a small-scale study focusing on students' experiences of assessment rather than on the outcome, we believe that our findings suggest implications for assessment practice and course design. Firstly, it is likely that the students' experiences were influenced by the order in which they were exposed to the assessment methods, and the educational environment which constituted the context of the study. The individual assessment method would probably not have been seen as such a successful tool for learning if it had been used late in the course. Moreover, this type of assessment may not have been regarded as an appropriate tool for learning by students in an educational environment with a strong emphasis on development of understanding, problem-solving and self-regulated learning. The group assessment method on the other hand, focusing on application and problem-solving in groups, could probably be used in a variety of educational settings.

Secondly, from a teaching point of view, the use of a number of complementary formative assessments throughout a course can help students to study consistently, and for some students this could be an important tool in helping them cope with the heavy workload. However, even if students can manage each individual assessment task on its own the set of tasks as a whole can be too demanding for them and they may become very selective in the tasks they focus on (Lindberg-Sand \& Olsson 2008; Scheja 2002).

Thirdly, the design of assessment tasks is up to the teacher and students' learning is likely to improve if teachers consciously use a series of assessment tasks to facilitate learning in a variety of ways. This view of assessment as an integral component of teaching and learning has been described by Keppell \& Carless (2006) as 'learning-oriented assessment'. Different assessment tasks have the potential to support student learning in different ways. By combining them, and by taking the educational and disciplinary context into consideration in the design of assessment tasks across a programme, we can develop more effective assessment practice.

\section{Acknowledgements}

Financial support was provided through the regional agreement on medical training and clinical research

(ALF) between Stockholm County Council and Karolinska Institutet (project number 20080167) and through Karolinska Institutet's funding for educational projects. The authors also wish to thank the students who participated in the study. 
M. Weurlander et al

Accepted version

\section{References}

Anderson, C. \& Hounsell, D. (2007). "Knowledge practices: 'doing the subject' in undergraduate courses." The Curriculum Journal, 18(4), 463 - 478.

Black, P., and Wiliam, D. (1998). "Assessment and classroom learning." Assessment in Education, 5(1), 7-74.

Boud, D. (2000). "Sustainable Assessment: rethinking assessment for the learning society." Studies in Continuing Education, 22(2), 151 - 167.

Caelli, K., Ray, L. \& Mill, J. (2003). “'Clear as Mud': Toward Greater Clarity in Generic Qualitative Research.” International Journal of Qualitative Methods, 2(2),1-13.

Carraccio, C., Wolfsthal, S. D., Englander, R., Ferentz, K., and Martin, C. (2002). "Shifting Paradigms: From Flexner to Competencies." Academic Medicine, 77(5), 361-367.

Carrillo-de-la-Peña, M., Baillès, E., Caseras, X., Martínez, À., Ortet, G., and Pérez, J. (2009). "Formative assessment and academic achievement in pre-graduate students of health sciences." Advances in Health Sciences Education, 14(1), 6167.

Charmaz, K. (2006). Constructing Grounded Theory: A Practical Guide Through Qualitative Analysis, London: SAGE Publications.

Corbin, J., and Strauss, A. (2008). Basics of Qualitative Research: Techniques and Procedures for Developing Grounded Theory, London: SAGE Publications.

Dahlgren, L.-O. (2005). "Learning conceptions and outcomes", in F. Marton, D. Hounsell, and N. Entwistle, (eds.), The Experience of Learning: Implications for teaching and studying in higher education. Edinburgh: University of Edinburgh, Centre for Teaching, Learning and Assessment, pp. 23-38.

Denzin, N. K., and Lincoln, Y. S. (2003). Collecting and Interpreting Qualitative Materials, Thousand Oaks, CA: SAGE Publications.

Entwistle, A., and Entwistle, N. (1992). "Experiences of understanding in revising for degree examinations." Learning and Instruction, 2(1), 1-22.

Entwistle, N. (1988). "Motivational factors in students' approaches to learning. Learning strategies and learning styles." in R. R. Schmeck, (ed.), Learning strategies and learning styles. Perspectives on individual differences. New York, NY, US: Plenum Press, pp. 21-51.

Entwistle, N. J., and Entwistle, A. (1991). "Contrasting forms of understanding for degree examinations: the student experience and its implications." Higher Education, 22(3), 205-227.

Falchikov, N. (2005). Improving Assessment Through Student Involvement: Practical solutions for aiding learning in higher and further education, New York: Routledge.

Gibbs, G. (1999). "Using assessment strategically to change the way students learn", in S. G. Brown, A., (ed.), Assessment Matters in Higher Education: Choosing and Using Diverse Approaches. Buckingham: SRHE \& Open University Press, pp. 41-53.

Hattie, J. \& Jaeger, R. (1998). "Assessment and Classroom Learning: a deductive approach.” Assessment in Education, 5(1), 111-122. 
Kember, D. (1996) "The intention to both memorise and understand: Another approach to learning?" Higher Education, 31(3), 341-354.

Keppell, M. \& Carless, D. (2006) "Learning-oriented assessment: a technology-based case study.", Assessment in Education, 13(2), 179-191.

Knight, P. (2006). "The local practices of assessment." Assessment and Evaluation in Higher Education, 31(4), 435-452.

Leach, J. \& Scott, P. (2003). "Individual and sociocultural views of learning in science education." Science and Education, 12(1), 91-113.

Lindberg-Sand, А. (2003). Kompetensbedömning eller prestationskonstroll? Examination som praktiserad kunskapssyn. [In Swedish] Utvärderingsenheten, Lunds universitet, Lund.

Lindberg-Sand, А̊., and Olsson, T. (2008). "Sustainable assessment?: Critical features of the assessment process in a modularised engineering programme." International Journal of Educational Research, 47(3), 165-174.

Marton, F., Hounsell, D. and Entwistle, N., (Eds.) (2005). "The Experience of Learning: Implications for teaching and studying in higher education. 3rd (Internet) edition". City: University of Edinburgh, Centre for Teaching, Learning and Assessment.: http://www.tla.ed.ac.uk/resources/EoL.html.

Marton, F., and Säljö, R. (1997). "Approaches to learning", in F. Marton, D. Hounsell, and N. Entwistle, (eds.), The experience of learning. Implications for teaching and studying in higher education. Edinburgh: Scottish Academic Press, pp. 39-59.

Nicol, D. J., and Macfarlane-Dick, D. (2006). "Formative assessment and self-regulated learning: a model and seven principles of good feedback practice." Studies in Higher Education, 31(2), 199 - 218.

Patton, M.Q. (2002). Qualitative Research \& Evaluation Methods, $3^{\text {rd }}$ Ed. Thousand Oaks: Sage Publications.

Ramsden, P. (1997). "The context of learning in academic departments", in F. Marton, D. Hounsell, and N. Entwistle, (eds.), The experience of learning. Implications for teaching and studying in higher education. Edinburgh: Scottish Academic Press, pp. 198-217.

Ramsden, P. (2003). Learning to teach in higher education, London: Routledge Falmer.

Sadler, D. R. (1989). "Formative assessment and the design of instructional systems." Instructional Science, 18, 119-144.

Sadler, D. R. (1998). "Formative Assessment: revisiting the territory." Assessment in Education, 5(1), 77 - 84.

Sambell, K., and McDowell, L. (1998). "The Construction of the Hidden Curriculum: messages and meanings in the assessment of student learning." Assessment and Evaluation in Higher Education, 23(4), 391 - 402.

Samuelowicz, K. \& Bain, J.D. (2002) 'Identifying academics' orientation to assessment practice", Higher Education, 43:173-201.

Scheja, M. (2002). Contextualising studies in higher education. First-year experiences of studying and learning in engineering, $\mathrm{PhD}$, Stockholm University.

Scheja, M., and Bonnevier, A. (in prep). "Conceptualising students' experiences of understanding in medicine." 
Scouller, K. (1998). "The influence of assessment method on students' learning approaches: Multiple choice question examination versus assignment essay." Higher Education, 35(4), 453-472.

Serafini, F. (2000-2001). "Three paradigms of assessment: measurement, procedure and inquiry" The Reading Teacher. City, pp. 384-.

Sfard, A. (1998). "On Two Metaphors for Learning and the Dangers of Choosing Just One." Educational Researcher, 27(2), 4-23.

Shepard, L. A. (2000). "The Role of Assessment in a Learning Culture." Educational Researcher, 29(7), 4-14.

Snyder, B. R. (1971). The Hidden Curriculum, Cambridge, MA: MIT Press.

Struyven, K., Dochy, F., and Janssens, S. (2005). "Students' perceptions about evaluation and assessment in higher education: a review." Assessment and Evaluation in Higher Education, 30(4), 325 - 341.

Säljö, R. (2000). Lärande i praktiken - ett sociokulturellt perspektiv. [In Swedish], Stockholm, Prisma.

Trowler, P., and Cooper, A. (2002). "Teaching and Learning Regimes: Implicit theories and recurrent practices in the enhancement of teaching and learning through educational development programmes." Higher Education Research and Development, 21(3), 221 - 240.

Vygotsky L. (1978). Mind in society: The development of higher psychological processes. Cambridge: Harvard University Press.

Yorke, M. (2003). "Formative assessment in higher education: Moves towards theory and the enhancement of pedagogic practice." Higher Education, 45(4), 477-501.

Wordcount: 6545 
M. Weurlander et al

Accepted version

Figure 1. A model of students' experiences of formative assessment as a tool for learning

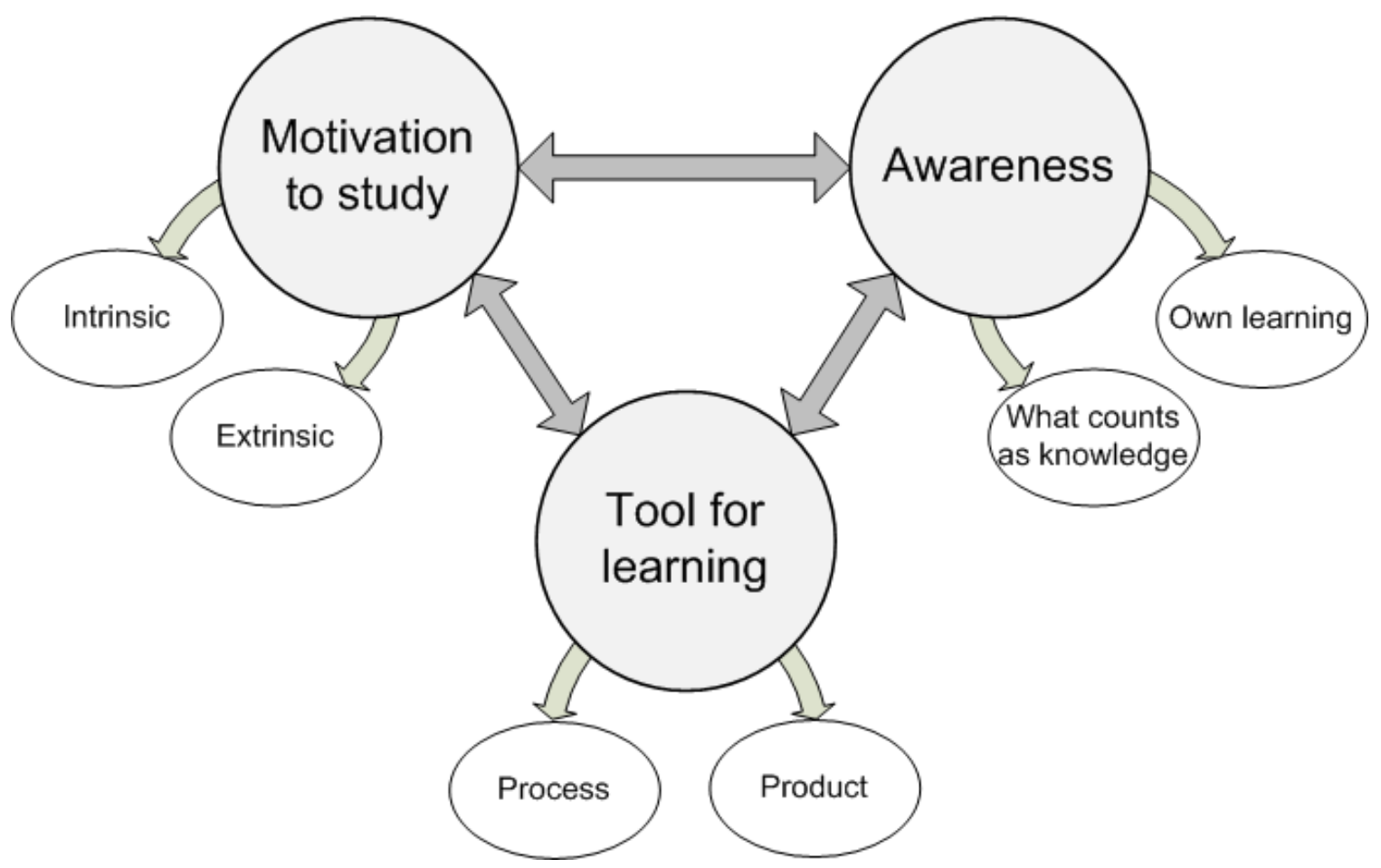




\section{Weurlander et al}

Accepted version

Table 1. A comparison between students' experiences of the individual and the group assessment

\begin{tabular}{lll}
\hline Theme & Written individual assessment & Oral group assessment \\
\hline Motivation to & External pressure and reward & Fear of disclosing lack of knowledge \\
study & trigger extrinsic motivation. & triggers extrinsic motivation and the \\
task itself triggers intrinsic motivation.
\end{tabular}

